\title{
Faktor Faktor Yang Mempengaruhi Lama Mencari Kerja Pada Tenaga Kerja Sektor Informal Di Kabupaten Manokwari
}

\author{
${ }^{1}$ Ida A. Baransano, ${ }^{2}$ Yuyun P. Rahayu, ${ }^{3}$ Lillyani M. Orisu \\ 1,2,3 Program Studi Ekonomi Pembangunan, Universitas Papua
}

Received: Desember 2018; Accepted: Januari 2019; Published: Maret 2019

\begin{abstract}
Abstrak
Tingkat pendidikan, umur dan pendapatan, secara parsial dan simultan berpengaruh terhadap lama mencari kerja di Kabupaten Manokwari. Data BPS Kabupaten Manokwari menunjukkan rasio pencari kerja cukup besar dan jumlah lowongan sangat terbatas (42:1). Persaingan antara para pencari kerja semakin kuat dan bergantung pada latar belakang pencari kerja. Selain itu, latar belakang pencari kerja yang kurang kuat berkontribusi pada semakin lamanya seseorang memperoleh pekerjaan. Penelitian ini merupakan jenis penelitian deskriptif kuantitatif dan sumber data meliputi data primer dan sekunder. Metode pengambilan sampel secara convenience sampling, jumlah sampel yang di ambil sebanyak 99 responden, teknik analisis data dalam penelitian ini menggunakan regresi linier berganda. Berdasarkan hasil analisis yang dilakukan dapat diketahui bahwa tingkat pendidikan berpengaruh negatif dan signifikan terhadap lama mencari kerja. Sedangkan umur berpengaruh positif dan tingkat pendapatan berpengaruh negatif terhadap kecepatan memperoleh pekerjaan seseorang, tetapi keduanya tidak berpengaruh signifikan pada taraf kepercayaan 95\%. Hasil pengujian menunjukan model regresi baik untuk dipergunakan dalam memprediksi. Sedangkan kemampuan variabel lama mencari kerja dijelaskan oleh variabel tingkat pendidikan, umur dan pendapatan sebesar $99.37 \%$.
\end{abstract}

Kata kunci: tingkat pendidikan, pendapatan, tenaga kerja

\begin{abstract}
The level of education, age and income, partially and simultaneously affect the length of time on seeking work in Manokwari Regency. BPS data shows the ratio of job seekers is quite large and the number of vacancies is very limited (42 job seekers per 1 job). Competition between job seekers is getting stronger and depends on the background of applicant. In addition, the lack of job seeker background contributes to the longer a person gets a job. This research is a type of quantitative descriptive research and data sources include primary and secondary data. The sampling method is convenience sampling, the number of samples taken is 99 respondents, the data analysis technique in this research is using multiple linear regression. Based on the results of the analysis, it can be seen that the level of education has a negative and significant effect on the length of work seeking. While age has a positive effect and income level has a negative effect on the speed of obtaining one's work, but both do not significantly influence the $95 \%$ level of confidence. While the ability of the old variable to find work is explained by the variables of education level, age and income of $99.37 \%$..
\end{abstract}

Keywords: level of education, income and employee

How to Cite: Baransano, I.A., Orisu, L.M., Rahayu, Y. P. (2019). Faktor Faktor Yang Mempengaruhi Lama Mencari Kerja Pada Tenaga Kerja Sektor Informal Di Kabupaten Manokwari. JFRES: Journal of Fiscal and Regional Economy Studies, 2 (1), 69 - 77.

\footnotetext{
Corresponding author :

E-mail: yp.rahayu@unipa.ac.id
} 


\section{PENDAHULUAN}

Pembangunan ekonomi pada hakekatnya adalah usaha dan upaya yang bertujuan untuk meningkatkan taraf hidup masyarakat, memperbesar kesempatan kerja, meningkatkan pemerataan pembagian pendapatan masyarakat, meningkatkan hubungan ekonomi dan mengusahakan pergeseran kegiatan ekonomi dari sektor primer ke sektor sekunder dan tersier (BPS, 2017).

Dari sisi konsumsi, pertumbuhan ekonomi yang tinggi dan berkelanjutan merupakan kondisi utama suatu keharusan bagi kelangsungan pembangunan ekonomi dan peningkatan kesejahteraan, karena jumlah penduduk bertambah setiap tahun, maka dibutuhkan penambahan pendapatan setiap tahun. Sedangkan sisi penawaran, pertumbuhan penduduk juga membutuhkan pertumbuhan kesempatan kerja (sumber pendapatan). Pertumbuhan ekonomi tidak dibarengi dengan pertambahan kesempatan kerja akan mengakibatkan ketimpangan dalam pembagian dari penambahan pendapatan tersebut (ceterisparibus), yang selanjutnya akan menciptakan suatu kondisi pertumbuhan ekonomi dengan peningkatan kemiskinan (Tambunan,2009).

Pemenuhan kebutuhan konsumsi dan kesempatan kerja itu sendiri hanya bisa dicapai dengan peningkatan output agregat (barang dan jasa) atau Gross Domestic Product (GDP)yang terus menerus. Dalam pemahaman ekonomi makro, pertumbuhan ekonomi adalah penambahan GDP, yang berarti peningkatan pendapatan nasional (NI). Pertumbuhan ekonomi tidak dapat diukur semata-mata dari pertumbuhan pendapatan atau pendapatan perkapita, namun harus pula melihat bagaimana pendapatan tersebut terdistribusi ke penduduk dan mengetahui siapa yang mendapat manfaat dari pembangunan tersebut (Todaro,1988).

Semakin meningkatnya jumlah angkatan kerja yang tidak disertai tersedianya lapangan pekerjaan yang cukup tentunya akan berkontribusi pada tingkat pengangguran yang tinggi. Adanya kesenjangan antara pertumbuhan jumlah angkatan kerja dan kemauan berbagai sektor perekonomian dalam menyerap tenaga kerja masih menjadi masalah utama di bidang perekonomian (Kuncoro,
2004). Berdasarkan tingkat pengangguran dapat dilihat kondisi suatu negara, apakah perekonomiannya berkembang atau lambat dan atau bahkan mengalami kemunduran. Selain itu, dengan tingkat pengangguran dapat ketahui pula ketimpangan atau kesenjangan distribusi pendapatan yang diterima suatu masyarakat negara tersebut Pengangguran bisa saja terjadi sebagai akibat tingginya tingkat perubahan angkatan kerja yang tidak diimbangi dengan adanya lapangan pekerjaan yang luas serta penyerapan dan persentasenya yang cenderung kecil yang disebabkan rendahnya tingkat pertumbuhan penciptaan lapangan kerja untuk menampung angkatan kerja siap pakai.

Peranan sumberdaya manusia yang meliputi jumlah dan kualitas sangat mutlak dibutuhkan dalam pembangunan. Dalam hubungannya dengan kualitas sumberdaya manusia, lapangan kerja sektor informal sangat penting dalam proses pembangunan dan proses modernisasi masyarakat yang sebagian besar masih bersifat tradisional atau semi-tradisional. Sebelum bekerja dan berusaha di sektor formal, tenaga kerja dari sektor tradisional berusaha dan bekerja terlebih dahulu disektor informal. Setelah mendapatkan pengalaman, keahlian dan pengetahuan di sektor informal, barulah mereka beralih ke sektor formal yang bersifat modern.Ini merupakan hal penting bagi negara berpenduduk besar, dimana sektor informal yang bersifat padat karya mampu menyerap tenaga kerja dalam jumlah besar (Kampana, 2009). Di Indonesia kedua fungsi sektor informal diatas sangat besar artinya. Selain menghadapi kelebihan penduduk juga diperhadapkan pada kondisi masyarakatnya yang masih dipengaruhi oleh unsur-unsur tradisional.Ada tiga hal penyebab lamanya tenaga kerja terdidik memperoleh pekerjaan, yaitu:

1. Ketimpangan struktural antara persediaan dan kesempatan kerja

2. Terlalu kuatnya pengaruh teori human kapital terhadap cara berpikir masyarakat

3. Program pendidikan yang dilihat dari tamatan SMA dan Sarjana yang paling cepat mendapatkan pekerjaan.

Banyak faktor yang mempengaruhi lama mencari kerja seseorang diantaranya adalah faktor usia, pendidikan dan pendapatan. Faktor 
usia sangat menentukan lamanya mencari kerja yakni semakin tua seseorang maka semakin lama pula untuk mendapatkan pekerjaan yang disebabkan waktu kerjanya tidak terlalu lama sehingga perusahaan akan mempekerjakan seseorang dengan berusia muda. Faktor pendidikan disini adalah perusahaan akan lebih mengutamakan tenaga kerja yang lebih mempunyai keahlian. Sedangkan pendapatan relative ditentukan oleh tingkat pendidikan formal pekerja yang lebih tinggi sehingga cenderung memilih pekerjaan sesuai keahlian dan pendapatannya.

Pranata (2014) menganalisis faktor upah (W), pendidikan (E), umur (Ag) dan jumlah tanggungan Keluarga (JTK) terhadap curahan jam kerja tenaga kerja sektor informal di Kota Semarang yang menyimpulkan bahwa sektor informal di Jawa Tengah telah mampu menopang angkatan kerja yang bekerja di sektor informal adalah sebesar $63 \%$. Sedangkan Iman (2012), menunjukkan bahwa variabel pendapatan keluarga bukanlah faktor yang mempengaruhi lama mencari kerja. Namun variabel pengalaman kerja, jenis kelamin, jenis sekolah, tingkat pendidikan, umur, dan status dalam rumah tangga memiliki pengaruh positif dan signifikan terhadap lama mencari kerja. Sehingga Azhar dan Herniwati (2013) menyatakan bahwa ketidakseimbangan antara jumlah pencari kerja terdaftar dengan jumlah lowongan kerja terdaftar di Kabupaten Purworejo akan menimbulkan masalah pengangguran dengan nilai Tingkat Partisipasi Angkatan Kerja (TPAK) sebesar 68,14\% dan yang paling rendah di antara daerah eks Karesidenan Kedua, Jawa Tengah.

Perekonomian Manokwari jika dilihat dari lajupertumbuhan PDRB ADHK Menurut Pengeluaran, cenderung mengalami pertumbuhan yang positif. Distribusi laju pertumbuhan PDRB ADHK tahun 2010menurut Pengeluaran Kabupaten Manokwari di tahun 2013 - 2017 mengalami fluktuasi dengan kisaran $9 \%$ sampai dengan $11 \%$ atau baik. Hal ini masih diatas tingkat pertumbuhan nasional adalah sebesar $8 \%$. Namun pertumbuhan tersebut tidak dibarengi dengan turunnya angka pengangguran berdasarkan laju pertumbuhan tenaga kerja. Jika terjadi pertumbuhan ekonomi, maka tenaga kerja yang terserap oleh sektor-sektor ekonomi juga mengalami peningkatan sehingga jumlah pengangguran menurun atau berkurang. Jumlah penduduk di Kabupaten Manokwari pada tahun 2015 adalah sebanyak 158.320 jiwa.Sebanyak 83.980 jiwa adalah laki- laki dan 74.340 jiwa adalah perempuan. Jika dibandingkan dengan proyeksi tahun 2014, mengalami pertumbuhan 2,60 \%. Sementara rasio jenis kelamin penduduk lakilaki terhadap penduduk perempuan tahun 2015 adalah 101,13 Selanjutnya jumlah angkatan kerja di tahun 2015 sebanyak 73.524 jiwa. Laki - laki sebanyak 46.606 jiwa dan perempuan sebanyak 26.918 jiwa. Sementara tingkat pengangguran adalah sebesar $6,58 \%$. Sedangkan jumlah bukan angkatan kerjasebesar 38.952 jiwa yang terdiri daripenduduk yang masih sekolah, mengurus rumah tangga, dan lainnya. Sehingga tingkat partisipasi angkatankerja adalah $65,37 \%$. Jika di dibandingkan dengan jumlah penduduk, maka rasio jumlah penduduk terhadap angkatan kerja laki-laki adalah $84.970: 46.606$ $=1,84$ atau 2 jiwa laki-laki yang artinya jika ada 2 orang laki - laki maka yang 1 adalah termasuk dalam angkatan kerja di tahun 2015. Sedangkan untuk perempuan adalah sebesar $75.315: 26.918=2,797$ atau 3 jiwa. Artinya, jika dari 3 perempuan tersebut maka 1 merupakan bagian dari angkatan kerja di Kabupaten Manokwari di tahun 2015 (BPS, 2017).

Selain pertumbuhan PDRB ADHK, rasio pencari kerja juga mengalami peningkatan. Terendah adalah ditahun 2014 yakni sebesar 13 : 1 pencari kerja atau sebanyak 13 pencari kerjaberusaha merebut 1 lowongan kerja di Kabupaten Manokwari. Sedangkan tertinggi adalah di tahun 2015 adalah sebesar $42: 1$ lowongan kerja. Untuk lebih jelasnya dapat terlihat pada Tabel 2 tentang jumlah pencari kerja dan lowongan kerja di Kabupaten Manokwari tahun 2014 - 2016.

Tingginya angka angkatan kerja, rasio pencari kerja dan rendahnya jumlah lapangan kerja yang berbanding terbalik dengan pertumbuhan ekonomi yang cenderung meningkat di Kabupaten Manokwari pada tahun 2014 2015 merupakan suatu kondisi yang menjadi masalah utama dalam pembangunan ekonomi umumnya mengatasi angka pengangguran, ketimpangan distribusi pendapatan dan kemiskinan sehingga para pengambil kebijakan daerah perlu melakukan reorientasi strategi pembangunan yang mampu menjawab 
persoalan mendasar, khususnya masalah pengangguran.

Tabel 1. Jumlah Pencari Kerja dan Lowongan Kerja berdasarkan Tingkat Pendidikan di Kabupaten Manokwari Tahun $2014-2016$

\begin{tabular}{crrrrr}
\hline \multirow{2}{*}{ Tahun } & \multicolumn{2}{c}{ Pencari Kerja } & \multicolumn{2}{c}{ Lowonang Kerja } & \multicolumn{2}{c}{ Rasio } \\
\cline { 2 - 6 } & Jumlah Orang & \% & Jumlah Orang & \% & \\
\hline 2014 & 13,554 & 48,64 & 1,068 & 75,96 & $13: 1$ \\
\hline 2015 & 14,311 & 51,36 & 338 & 24,03 & $42: 1$ \\
\hline Jumlah & 27,865 & 100,00 & 1,406 & 100,00 & \\
\hline
\end{tabular}

Sumber: BPS Kabupaten Manokwari,2017

Tabel 2. Jumlah Pengangguran Terbuka dan Lowongan Kerja Berdasarkan Usia Produktif Tahun 2014 - 2015

\begin{tabular}{|c|c|c|c|c|c|}
\hline \multirow{2}{*}{ Tahun } & \multicolumn{2}{|c|}{ Pengangguran Terbuka } & \multicolumn{2}{|c|}{ Lowonang Kerja } & \multirow[t]{2}{*}{ Rasio } \\
\hline & Jumlah Orang & $\%$ & Jumlah Orang & $\%$ & \\
\hline 2014 & 2,634 & 35,25 & 1,068 & 75,96 & $13: 1$ \\
\hline 2015 & 4,837 & 64,74 & 338 & 24,03 & 14: 1 \\
\hline Jumlah & 7,471 & 100,00 & 1,406 & 100,00 & \\
\hline
\end{tabular}

Sumber: BPS Kabupaten Manokwari,2017 
Pada tabel 2 dapat di jelaskan bahwa pada tahun 2014 rasio pengangguran terbuka lebih baik dibandingkan dengan lowongan kerja sedangkan pada tahun 2015 jumlah pengangguran terbuka kerja semakin sulit memperoleh pekerjaan karena kesempatan kerja semakin sempit, dimana 14 orang pengangguran memperebutkan 1 kesempatan untuk mendapatkan lowongan kerja. Penelitian ini mendalami tentang tingginya rasio pencari kerja pertahun yang berbanding terbalik dengan naiknya PDRB ADHK Tahun 2010 Kabupaten Manokwari dan berimplikasi pada pertumbuhaan ekonomi yang cenderung meningkat di tahun 2013 - 2017 dengan rata-rata pertumbuhan sebesar 9 \% sampai $11 \%$ (BPS Kab. Manokwari, 2017).

Jika terjadi pertumbuhan ekonomi di suatu daerah maka implikasinya adalah meningkatnya lapangan kerja (lowongan kerja) yang dapat menyerap angkatan kerja sehingga angka pengangguran dan kemiskinan pun dapat menurun. Bertolak dari pemahaman bahwa jika terjadi pertumbuhan ekonomi maka secara otomatis harus dapat mendorong luasnya lapangan kerja yang menjadi lowongan kerja bagi pencari kerja. Namun kenyataannya kondisi ini tidak berlaku di Kabupaten Manokwari di tahun 2013 - 2017. Dengan demikian pertanyaan penelitian adalah faktor-faktor apasaja yang mempengaruhi lama mencari kerja bagi tenaga kerja khususnya sektor informal di Kabupaten Manokwari.

\section{METODE PENELITIAN}

Metode kuantitatif digunakan untuk menganalisis faktor-faktor yang mempengaruhi lama mencari kerja seorang tenaga kerja. Populasi dalam penelitian ini adalah semua pencari kerja tahun 2015 berdasarkan data BPS pada tabel 1 yang berjumlah 14.311 jiwa untuk Kabupaten Manokwari. Teknik pengambilan sampel dalam penelitian ini dilakukan dengan teknik Sampling Insidental, teknik penentuan sampel berdasarkan kebetulan, yaitu siapa saja yang menjadi kebetulan/insidental bertemu dengan peneliti dapat digunakan sebagai sampel, bila dipandang orang yang kebetulan ditemui itu cocok sebagai sumber data (Sugiyono, 2008). Perhitungan jumlah sampelnya menggunakan metode Slovin (Umar, 2008) dengan hasil 99 orang responden sampel.

$$
n=\frac{N}{1+N e 2}
$$

dimana :

$\mathrm{n}=$ Ukuran Sampel

$\mathrm{N}=$ Jumlah Populasi $=14.311$

$\mathrm{e}=$ tingkat kesalahan $10 \%$

$$
n=\frac{14.311}{1+14.311(10 \%)^{2}}=99,31 \approx 99
$$

Sumber data yang diperlukan dalam penelitian ini terdiri dari data primer dan data sekunder. Data Primer merupakan informasi yang dikumpulkan peneliti langsung dari sumbernya. Data primer yang digunakan dalam penelitian ini adalah hasil pengisian kuisioner (angket) oleh responden, yaitu para pekerja di Kabupaten Manokwari. Data sekunder merupakan data yang disimpulkan dan diterbitkan instansi atau lembaga yang relevan dengan penelitian. Dalam penelitian ini data diperoleh dari BPS Kabupaten Manokwari.

Teknik pengumpulan data yang digunakan pada penelitian ini adalah berdasarkan angket (kuisioner). Kuesioner adalah suatu cara pengumpulan data dengan memberikan atau menyebarkan daftar pertanyaan kepada responden, dengan harapan mereka akan memberikan respon atas daftar pertanyaan tersebut (Umar, 2008).

Penelitian ini dilatarbelakangi kenyataan bahwa adanya peningkatan pada jumlah pencari kerja di Kabupaten Manokwari pada sektor informal, sedangkan ketersedian lowongan kerja sangat terbatas. Hal ini mengindikasikan perlunya peningkatan ketersediaan lowongan kerja oleh pemerintah ataupun pihak swasta untuk mengurangi kesenjangan. Adapun kerangka hubungan variabel dapat dilihat pada gambar 1 .

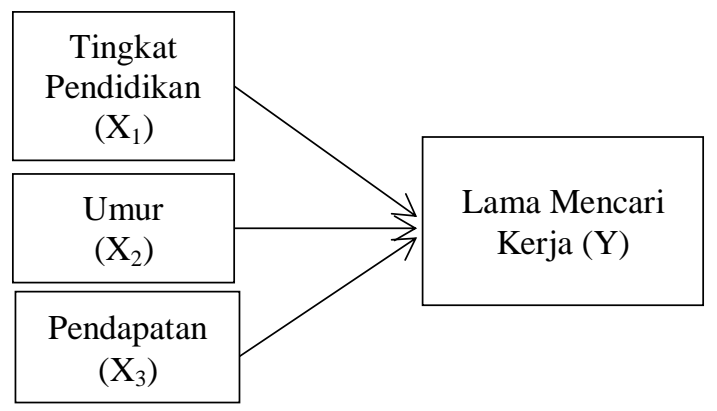

Gambar 1. Kerangka Hubungan Variabel

Keterangan $: \longrightarrow=$ mempengaruhi 
Berdasarkan hubungan antar tujuan penelitian serta kerangka pemikiran teoritis terhadap rumusan masalah penelitian ini maka hipotesis yang akan diajukan adalah sebagai berikut :

$\mathrm{H}_{0}=$ diduga tingkat pendidikan (X1), umur (X2), pendapatan (X3) tidak berpengaruh terhadap lama mencari kerja $(\mathrm{Y})$.

$\mathrm{H}_{1}=$ diduga tingkat pendidikan (X1), umur (X2), pendapatan (X3) berpengaruh terhadap lama mencari kerja $(\mathrm{Y})$.

Metode analisis yang digunakan dalam penelitian ini adalah metode analisis statistik deskriptif. Analisis statistik deskriptif adalah statistik yang digunakan untuk menganalisis data dengan cara mendeskripsikan atau mengambarkan data yang telah terkumpul sebagaimana adanya tanpa bermaksud membuat kesimpulan yang berlaku untuk umum (Sugiyono, 2008). Alat analisis data yang digunakan dalam penelitian ini adalah analisis korelasional. Regresi linear berganda kemudian digunakan untuk menentukan hubungan tersebut signifikan atau tidak.

$\mathrm{Y}=\mathrm{b} 0+\mathrm{b}_{1} \mathrm{X}_{1}+\mathrm{b}_{2} \mathrm{X}_{2}+\mathrm{b}_{3} \mathrm{X}_{3}+\mathrm{e}$

Keterangan :

$\mathrm{Y}=$ Lama Mencari Kerja (Bulan)

$\mathrm{X}_{1}=$ Tingkat pendidikan (Skor $0=$ tidak sekolah, Skor $1=$ SD, Skor $2=$ SMP, Skor 3 = SMA, Skor 4 = Perguruan Tinggi).

$\mathrm{X}_{2}=$ Usia (Tahun)

$\mathrm{X}_{3}=$ Pendapatan (Rupiah/Bulan)

$b_{i}=$ Koefisien Regresi, $i=1,2,3, \ldots n$

$\mathrm{b}_{0}=$ Nilai konstanta

$\mathrm{e}=$ Standar Error

Selanjutnya uji statistik dan uji asumsi klasik dilakukan untuk memperoleh hasil analisis regresi yang memenuhi asumsi BLUE (Best Linear Unbiased Estimator).

\section{HASIL DAN PEMBAHASAN}

\section{Statistik Deskriptif}

Gambaran tentang responden yang menjadi sampel dalam penelitian ini diklasifikasikan berdasarkan jenis kelamin, usia, pendidikan, asal daerah dan status kependudukan. Distribusi responden disajikan dalam Tabel 3. Responden yang berjenis kelamin laki-laki lebih banyak (61,62 persen). Karena perusahaan atau pemilik usaha lebih membutuhkan tenaga kerja laki-laki di bandingkan tenaga kerja perempuan. Kelompok usia responden didominasi oleh usia produktif kelompok umur 20-49 sebesar 83 jiwa atau 83.84 persen. Responden tingkat pendidikan terakhir yang paling banyak dalam lama mencari kerja berada pada tingkat pendidikan SMA sebanyak 68 jiwa atau 68.69 persen. Responden bukan asli Papua lebih besar dan penduduk asli Papua sedikit 22 jiwa atau 22.22 persen berdasarkan KTP (Kartu Tanda Penduduk) Kabupaten Manokwari. Sedangkan untuk tenaga kerja responden yang perantau sebesar 77 jiwa atau 77.78 persen.

Tabel 3. Responden menurut Jenis Kelamin, Usia, Pendidikan Terakhir Dan Status Kependudukan

\begin{tabular}{|c|c|c|c|}
\hline No & Kategori & $\begin{array}{c}\text { Jumlah } \\
\text { (Jiwa) }\end{array}$ & $\begin{array}{c}\text { Persen } \\
(\%)\end{array}$ \\
\hline $\mathrm{A}$ & \multicolumn{3}{|c|}{ Jenis Kelamin } \\
\hline 1 & Laki-Laki & 61 & 61,62 \\
\hline 2 & Perempuan & 38 & 38,38 \\
\hline & Total & 99 & 100,00 \\
\hline $\mathrm{B}$ & \multicolumn{3}{|c|}{ Umur } \\
\hline 1 & $<20$ & 16 & 16,16 \\
\hline 2 & $20-49$ & 83 & 83,84 \\
\hline 3 & $>50$ & 0 & 0 \\
\hline & Total & 99 & 100,00 \\
\hline $\mathrm{C}$ & \multicolumn{3}{|c|}{ Tingkat Pendidikan } \\
\hline 1 & Tidak Sekolah & 1 & 1,01 \\
\hline 2 & SD & 2 & 2,02 \\
\hline 3 & SMP & 22 & 22,22 \\
\hline 4 & SMA & 68 & 68,69 \\
\hline 5 & Perguruan Tinggi & 6 & 6,06 \\
\hline & Total & 99 & 100,00 \\
\hline $\mathrm{D}$ & \multicolumn{3}{|c|}{ Asal Daerah } \\
\hline 1 & Papua & 22 & 22,22 \\
\hline 2 & Non Papua & 77 & 77,78 \\
\hline & Total & 99 & 100,00 \\
\hline $\mathrm{E}$ & \multicolumn{3}{|c|}{ Status Kependudukan } \\
\hline 1 & Penduduk Asli Papua & 52 & 52,52 \\
\hline 2 & $\begin{array}{l}\text { Penduduk Luar } \\
\text { Papua }\end{array}$ & 47 & 47,48 \\
\hline
\end{tabular}

Sumber: Data primer diolah, 2019

Dari tabel 4 diketahui bahwa rata-rata lama mencari kerja sebesar 9,34 bulan dan standar deviasinya (tingkat sebaran data) sebesar 13,88 dengan jumlah sampel 99 tenaga kerja. Rata-rata tingkat pendidikan rsponden adalah SMA (skor 3). Rata-rata umur sebesar 25,36 atau 25 tahun yang merupakan umur produktif. Rata-rata pendapatan sebesar 2,20 atau Rp. 2,2 juta /bulan. 
Tabel 4. Statistik Deskriptif

\begin{tabular}{lrr}
\hline \multicolumn{1}{c}{ Variabel } & Mean & Std.Deviation \\
\hline Lama Mencari Kerja & 9,34 & 13,88 \\
\hline Tingkat Pendidikan & 2,72 & 0,77 \\
\hline Umur & 25,36 & 6,56 \\
\hline Pendapatan & 2,20 & 0,54 \\
\hline
\end{tabular}

Sumber: Data Primer Diolah, 2018

\section{Uji Simultan (Uji F)}

Uji pengaruh silmultan dilakukan dengan tujuan untuk mengetahui apakah variabel independen tingkat pendidikan, umur dan pendapatan secara bersama sama atau silmultan mempengaruhi variabel dependen lama mencari kerja.

Tabel 5. Hasil Uji Simultan (Uji F )ANOVA

\begin{tabular}{lrrrrr}
\hline \multicolumn{1}{c}{ Model } & Sum of Squares & \multicolumn{1}{c}{ df } & Mean Squares & F & \multicolumn{1}{c}{ Sig } \\
\hline Regression & $1.180,15$ & 3 & 393,38 & 2,10 & $0,10^{\mathrm{b}}$ \\
\hline Residual & $17.529,93$ & 94 & 186,48 & & \\
\hline Total & $18.710,08$ & 97 & & & \\
\hline
\end{tabular}

a. Dependent Variable: Lama mencari kerja

b. Predictors: (Constant), Pendapatan X3, Umur X2, Tingkat Pendidikan X1

Sumber : Data Primer Diolah ,2018

Dari tabel 5 di dapatkan $F$ hitung sebesar 2.10 diperoleh nilai $0,10>0,05$ berarti secara bersamasama (simultan), variabel tingkat pendidikan, umur dan pendapatan tidak berpengaruh dan tidak signifikan terhadap lama mencari kerja dalam tingkat kepercayaan 95 persen atau probabilitas 0,05. Namun dalam tingkat kepercayaan 90 persen secara bersama-sama variabel tingkat pendidikan, umur, pendapatan berpengaruh signifikan terhadap lama mencari kerja.

\section{Uji Asumsi Klasik}

\section{Uji Normalitas}



Gambar 2. Uji Normal P-P Plot of regresision standardized Residual

Uji normalitas bertujuan untuk menguji apakah dalam model regresi, variabel pengangguran atau residul memiliki distribusi normal Uji normalitas pada prinsipnya dapat dideteksi dengan penyebaran data (titik) pada sumbu diagonal dari diagonal grafik atau dengan histogram pada residualnya. Jika data menyebar disekitar garis diagonal dan mengikuti arah garis diagonal atau grafik histogrammnya menunjukkan pola distribusi normal, maka model regresi memenuhi asumsi normalitas.

Berdasarkan hasil pengelolahan data maka dilihat bahwa semua data bedistribusi secara normal dan tidak terjadi penyimpangan. Hal ini dapat dilihat dengan sebaran data yang menyebar di sekitar garis diagonal pada “ normal P-P Plot of Regresion Standardized Residual ". Titik-titik pada gambar 2 mengikuti arah garis diagonal, sehingga dapat dikatakan bahwa model regresi dalam penelitian ini berdistribusi normal.

\section{Uji Multikolinearitas}

Uji multikolinearitas dilakukan untuk menguji apakah model regresi ditemukan adanya korelasi antar variabel independen. Jika terjadi korelasi, maka dinamakan terdapat problem multikolinearitas. Model regresi yang baik seharusnya tidak terjadi korelasi diantara variabel independen. Pengujian ada tidaknya gejala multikolinearitas dilakukan dengan memperhatikan nilai matriks korelasi yang dihasilkan pada saat pengelolahan data serta nilai VIF (variance inflation factor) dan tolerance-nya. Nilai dari VIF yang kurang dari 
10 dan tolerance yang lebih dari 0,10 maka menyatakan tidak terjadi multikolinearitas.

Tabel 6. Hasil Uji Multikolinieritas

\begin{tabular}{|l|c|c|}
\hline \multirow{2}{*}{\multicolumn{1}{c}{ Model }} & \multicolumn{2}{|c|}{ Collinearity Statistics } \\
\cline { 2 - 3 } & Tolerance & VIF \\
\hline Tingkat Pendidikan (X1) & 0.96 & 1.04 \\
\hline Umur ( X2) & 0.98 & 1.01 \\
\hline Pendapatan ( X3) & 0.94 & 1.05 \\
\hline
\end{tabular}

Dependent Variable: Lama Mencari Kerja Y

Sumber: Data primer diolah, 2018

Dari ketentuan yang ada bahwa jika nilai VIF < 10 dan tolerance $>0,10$ maka tidak terjadi gejala multikolinearitas dan nilai - nilai yang di dapat dari perhitungan adalah sesuai denga ketetapan nilai VIF dan tolerance, dari hasil analisis diatas dapat diketahui nilai toleransi semua variabel independen (tingkat pendidikan, umur dan pendapatan) lebih dari 0,10 dan nilai VIF kurang dari 10 maka dapat disimpulkan bahwa variabel independenya tidak terjadi multikolinearitas sehingga model tersebut telah memenuhi syarat asumsi klasik dalam analisis regresi.

\section{Uji Autokorelasi}

Uji autokorelasi bertujuan untuk menguji apakah dalam model regresi terdapat korelasi diantara kesalahan pengganggu dalam periode tertentu.

Tabel 7. Hasil Uji Autokorelasi

\begin{tabular}{clll}
\hline $\mathbf{R}$ & $\begin{array}{l}\mathbf{R} \\
\text { square }\end{array}$ & $\begin{array}{l}\text { AdjustedR } \\
\text { square }\end{array}$ & $\begin{array}{l}\text { Durbin } \\
\text { Watsom }\end{array}$ \\
\hline $0.251^{\mathrm{a}}$ & 0.063 & 0.033 & 1.814 \\
\hline
\end{tabular}

a. Predictors: (Constant), pendapatan $X_{3}, \quad$ umurX $X_{2}$, tingkat pendidikan $\mathrm{X}_{1}$

b. Dependent Variable: Lama mencari kerjaY

Sumber: Data Primer Diolah, 2018

Hasil analisis regresi dengan menggunakan angka 1.814. nilai $\mathrm{dL}$ dan $\mathrm{dU}$ didapat dengan melihat dari tabel durbin - Watson dengan $\mathrm{n}=$ 99 dan $\mathrm{k}=3$ Nilai $\mathrm{dL}$ sebesar 1,6108 dan nilai dU sebesar 1.7355 oleh karena itu DW 1.814 lebih besar dari batas atas $(\mathrm{dU})=1,7355$ dan kurang dari 4-1.7355 ( $\mathrm{dU}<\mathrm{DW} \leq 4$-dU atau $1.7355<1,814 \leq 2,2645$ ). Maka dapat disimpulkan bahwa tidak ada autokorelasi positif maupun negative dan dapat disimpulkan tidak terdapat autokorelasi.

\section{Uji Heteroskedasitas}

Tujuan dari uji Heteroskedasitas untuk mengetahui ada tidaknya terjadi ketidaksamaan variance dari residual satu pengamatan ke pengamatan yang lain. Jika varians dan residual satu pengamatan ke pengamatan yang lain tetap, maka disebut homokesdasitsitas dan jika berbeda maka disebut heteroskedastistas.



Sumber: Data Primer Diolah

Gambar 3. Uji Heteroskedastisitas

Dari hasil analisis Uji Run menggunakan SPSS dapat diketahui bahwa titik-titik yang menyebar secara acak baik diatas maupun dibawah angka nol pada sumbu Y. serta tidak membentuk pola atau kecenderungan tertentu pada diagram plot. Sehingga dapat disimpulkan tidak terjadi adanya heteroskedastisitas dan model regresi tersebut dapat digunakan untuk memprediksi lama mencari kerja secara keseluruhan jadi dapat disimpulkan bahwa model regresi memenuhi syarat BLUE.

Tabel 8. Hasil Heteroskedastisitas

\begin{tabular}{lr}
\hline \multicolumn{1}{c}{ Model } & Sig \\
\hline Constant & 1,00 \\
\hline Tingkat Pendidikan $\left(\mathrm{X}_{1}\right)$ & 1,00 \\
\hline Umur $\left(\mathrm{X}_{2}\right)$ & 1,00 \\
\hline Pendapatan $\left(\mathrm{X}_{3}\right)$ & 1,00 \\
\hline
\end{tabular}

a. Dependent Variable: Unstandardized Residual

Sumber: Data Primer Diolah, 2018

Dari tabel 8 dapat dilihat dari nilai signifikan pada variabel Tingkat pendidikan (X1) nilai signifikan 1,00, nilai variabel Umur (X2) nilai signifikan 1,00 , begitu juga nilai variabel pendapatan (X3) nilai signifikan 1,00, semuanya diatas probabilitas Lama mencari kerja yaitu 0.05 maka model regresi tidak mengandung heteroskedastistas. 


\section{Hasil Analisis Regresi Linier}

Berdasarkan uji regesi linier berganda yang telah dilakukan, diperoleh hasil estimasi regresi linier berganda pada tabel 9. Dalam bentuk persamaan regresi linear berganda dapat ditulis sebagai berikut :

$$
\begin{aligned}
\operatorname{Lag} Y= & 22.18-4.31 \operatorname{Lag} x_{1} \\
& +0.04 \operatorname{Lag} x_{2}-0.99 \operatorname{Lag} x_{3}
\end{aligned}
$$

Keterangan:

Y : Lama Mencari Kerja (Bulan)
$\mathrm{X}_{1}$ : Tingkat Pendidikan (Skor Tidak Sekolah $=0$; $\mathrm{SD}=1 ; \mathrm{SMP}=2 ; \mathrm{SMA}=3 ;$ PerguruanTinggi $=4$ )

$\mathrm{X}_{2}:$ Umur (Tahun)

$\mathrm{X}_{3}$ : Pendapatan (Rupiah/bulan)

Dari tabel 9 dapat diketahui bahwa nilai koefisien sebesar 22.180 dan jika tingkat pendidikan $\left(\mathrm{X}_{1}\right)$, umur $\left(\mathrm{X}_{2}\right)$ dan pendapatan $\left(\mathrm{X}_{3}\right)$ nilainya adalah 0 , maka lama mencari kerja $(\mathrm{Y})$ nilainya adalah 22.180 .

\begin{tabular}{|c|c|c|c|c|c|}
\hline \multirow{2}{*}{ Model } & \multicolumn{2}{|c|}{ Unstandardized Coefficients } & \multirow{2}{*}{$\begin{array}{c}\begin{array}{c}\text { Standardized } \\
\text { Coefficients }\end{array} \\
\text { Beta } \\
\end{array}$} & \multirow[t]{2}{*}{$\mathbf{T}$} & \multirow[t]{2}{*}{ Sig } \\
\hline & B & Std. Error & & & \\
\hline (constant) & 22.18 & 8.51 & & 2.60 & 0.01 \\
\hline Lag Tingkat Pendidikan (X1) & -4.30 & 1.82 & -0.24 & -2.35 & -0.02 \\
\hline Lag Umur (X2) & 0.04 & 0.21 & 0.02 & 0.19 & 0.84 \\
\hline Lag Pendapatan (X3) & -0.99 & 2.60 & -0.03 & -0.38 & 0.70 \\
\hline
\end{tabular}

Tabel 9. Coefficients

a. Dependent Variable: Lag Lama Mencari Kerja.

Sumber : Data Primer Diolah, 2018

\section{Uji Statistik}

\section{Uji Parsial ( Uji T)}

Ujit digunakan untuk mengetahui apakah variabel - variabel independen secara parsial berpengaruh terhadap variabel dependen. Tingkat signifikan yang digunakan adalah 0,05 hasil uji $\mathrm{t}$ yang dilihat dari hasil regresi pada tabel 5.6 adalah sebagai berikut:

a. Variabel Tingkat pendidikan (X1) terhadap Lama Mencari Kerja $(Y)$

dapat Dilihat dalam tabel 5.6 dari hasil regresi terdapat nilai $\mathrm{t}$ hitung sebesar 0.02 dannilai signifikan $|-0,02|<0,05$ ini berati, H1 diterima dan H0 ditolak, Artinya hipotesis yang menyatakan bahwa variabel tingkat pendidikan (X1) berpengaruh signifikan terhadap variabel (Y) lama mencari kerja.Hasil penelitian ini sma dengan penelitian Mariska, dkk. (2016) yang menjelaskan bahwa ada pengaruh positif dan signifikan antara tingkat pendidikan secara parsial terhadap lama mencari kerja.

\section{b. Variabel Umur $\left(X_{2}\right)$ Terhadap Lama Mencari Kerja}

dapat Dilihat dalam tabel 5.6 dari hasil regresi terdapat nilai $\mathrm{t}$ hitung sebesar 0,84 dannilai signifikan $0.84>0,05$ ini berati, H1ditolak dan HOditerima,Artinya hipotesis yang menyatakan bahwa variabel umur (X2) berpengaruh signifikan terhadap variabel (Y) lama mencari kerja. Hasil penelitian ini sma dengan penelitian Mahendra (2014) yang menjelaskan bahwa ada pengaruh positif dan signifikan antara umur secara parsial terhadap lama mencari kerja.

a. Variabel Pendapatan $\left(X_{3}\right)$ Terhadap Lama Mencari kerja

dapat Dilihat dalam tabel 5.6 dari hasil regresi terdapat nilai $\mathrm{t}$ hitung sebesar 0,70 dannilai signifikan $0,70>0,05$ ini berati, H1ditolak dan HOditerima, Artinyahipotesis yang menyatakan bahwa variabel pendapatan (X3) tidak berpengaruh signifikan terhadap variabel (Y) lama mencari kerja. Hasil penelitian ini sma dengan penelitian Suroso (2012) yang menjelaskan bahwa pendapatan berpengaruh terhadap lama mencari dimana pencari kerja dengan tingkat pendapatan yang lebih tinggi maka akan lebih cepat memperoleh pekerja.

\section{Koefisien Determinasi $\left(R^{2}\right)$}

Koefisien determinasi dalam regresi linier berganda digunakan untuk mengukur presentase sumbangasi pengaruhi variabel Tingkat pendidikan $\left(\mathrm{X}_{1}\right)$,Umur $\left(\mathrm{X}_{2}\right)$ dan Pendapatan $\left(\mathrm{X}_{3}\right)$ terhadap variabel lama mencari kerja (Y). Nilai koefisien determinasi dapat di lihat pada tabel 10.

Tabel 11. Model Summary

$\begin{array}{ccc}\mathbf{R} & \text { R square } & \text { Adjusted R Square } \\ 0.251 & 0.063 & 0.033\end{array}$

a.prredictors: (Constant), pendapatan $\mathrm{X}_{3}$, umur $\mathrm{X}_{2}$, tingkat pendidikan $\mathrm{X}_{1}$

b.Dependent Variabel: Lama mencari kerja Y

Sumber: Data Primer yang Diolah, 2018 
Berdasarkan tabel 10 angka $\mathrm{R}^{2}$ sebesar 6,3 persen. Nilai $R^{2}$ yang kecil berarti kemampuan variabel-variabel independen dalam menjelaskan variabel-variabel dependen sangat terbatas. Hasil ini menunjukkanbahwa presentase sumbangan pengaruh variabel tingkat pendidikan umur dan pendapatan terhadap variabel lama mencari kerja sebesar 6,3 persen Variasi variabel lama mencari kerja sedangkan sisanya sebesar 99,37 persen dipengaruhi oleh variabel variabel lainnya yang tidak diteliti.

\section{Pembahasan Hasil Penelitian Regresi}

Dari persamaan regresi dapat diketahui bahwa nilai koefisien lama mencari kerja sebesar 22.18. Jika tingkat pendidikan $\left(\mathrm{X}_{1}\right), \operatorname{Umur}\left(\mathrm{X}_{2}\right)$ dan Pendapatan $\left(X_{3}\right)$ nilainya adalah 0 maka lama mencari kerja nilainya 22.18 .

Nilai koefisien regresi variabel tingkat pendidikan adalah -4.30 dimana variabel tingkat pendidikan berpengaruh negative dan signifikan.Jika skor tidak/belum sekolah (0), SD (1), SMP (2), SMA (3) dan Perguruan Tinggi, (4) artinya bahwa semakin tinggi tingkat pendidikan menyebabkan seseorang pencari kerja memperoleh pekerjaan lebih cepat. Hasil penelitian ini sama dengan penelitian Mariska (2016) yang menjelaskan bahwa semakin tinggi tinggi tingkat pendidikan maka seseorang pencari kerja memperoleh pekerjaan dengan cepat sesuai pekerjaan yang diinginkan.

Nilai koefisien regresi variabel umur adalah 0.04 dimana hasil variabel umur berpengaruh positif tetapi tidak signifikan. Pada taraf kepercayaan 95\%. Jika umur bertambah satu tahun,sebesar0.04atau selama sehari maka akan menambah memperpanjang waktu untuk memperoleh pekerjaan.Hal ini sejalan dengan penelitian Herawati (2013) yangmenjelaskan bahwa bertamabahnya usia seseorang akan lebih sulit baginya untuk memperoleh pekerjaan.

Nilai koefisien regresi variabel pendapatan adalah -0.99 dimana hasil variabel pendapatan berpengaruh negatif dan tidak signifikan. Jika kenaikan pendapatan satu juta rupiah,makasemakincepat memperoleh pekerjaan atau mengurangi lama mencari kerja sebanyak 1 bulan. Hal ini tidak sejalan dengan penelitian Mariska (2016) yang menyatakan bahwa nilai signifikansi pada penelitian ini dimana koefisien regresi pendapatan mempengaruhi dan signifikan, maka semakin tingginya pendapatan dan juga memperoleh pekerjaan dengan cepat.

\section{KESIMPULAN}

Dari analisis data yang telah dilakukan dapat diperoleh kesimpulan bahwa variabel tingkat pendidikan, berpengaruh negatif tetapi tidak signifikan. Berarti bahwa semakin tinggi tingkat pendidikan pencari kerja akan semakin lama waktu yang digunakan untuk mencari kerja. Variabel umur berpengaruh positif terhadap lama mencari kerja. Berarti bahwa semakintua umur pencari kerja akan semaki lama waktu yang digunakan untuk mencari kerja. Selanjutnya, variabel pendapatan memiliki berpengaruh positif terhadap lama mencari kerja. Berarti bahwa semakin tua umur pencari kerja akan semakin tinggi pendapatan yang digunakan untuk mencari kerja. Secara keseluruhan variabel-variabel independen dalam model yang dihasilkan belum mampu secara nyata menjelaskan variasi variabel dependen $\left(\mathrm{R}^{2}=\right.$ $0.063 \%)$.

\section{DAFTAR PUSTAKA}

BPS Kabupaten Manokwari, 2017. Kabupaten Manokwari dalam angka 2017, Manokwari.

Kuncoro, Madrajat, 2004. Ekonomi dan Pembangunan Daerah:Reformasi, Perencanaan, Strategi, dan Peluang. Jakarta; Penebit Erlanga.

Mahendra ,2014. Analisis Pengaruh Pendidikan ,Upah Jenis Kelamin Usia Dan Pengalaman Kerja Tehadap Produktivitas Tenaga Kerja,Universitas Diponorego Semarang.

Mariska, dkk, 2016.Faktor - Faktor Yang Mempengaruhi Lama Mencari Kerja Tenaga Kerja Terdidik Pada Pemerintahan Kota PrabumulihPurworejo, Skripsi ProgramPasca Sarjana Universitas Sriwijaya Palembang.

Sugiyono, 2008. Metode Penelitian Kualitatif, Kuantitatif, dan $R \& D$. Cetakan ke 17. Penerbit Alfabeta Bandung.

Todaro, 1998. Pembangunan Ekonomi Dunia ke 3. Jakarta : Penerbit Erlangga. 